DOI: $10.7242 / 2658-705 X / 2019.4 .3$

УДК 532.5:556.18

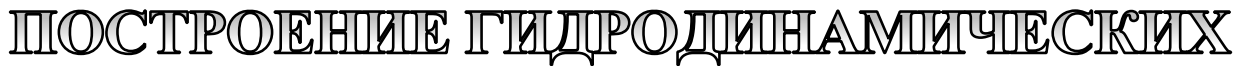

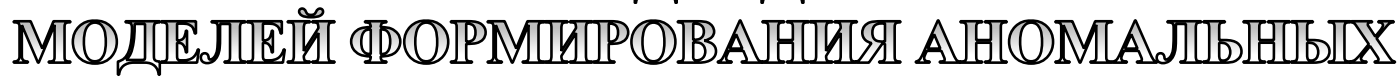

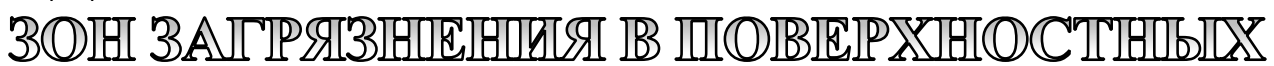 BOLDHULIXX OIBDEIKTAXX *
}

Т.П. Любимова, Институт механики сплошных сред УрО РАН

Я.Н. Паршакова, Институт механики сплошных сред УрО РАН

Д.С. Голдобин, Институт механики сплошных сред УрО РАН

А.П. Лепихин, Горный институт УрО РАН;

Пермский государственный национальный исследовательский университет

Работа посвящена построению гидродинамических моделей формирования аномальных зон загрязнения в поверхностных водных объектах. Целью исследования является установление физических механизмов и условий, при которых наблюдается формирование таких зон. Конкретными задачами, на решение которых направлено исследование, являются задачи:

- о существенном ослаблении поперечного перемешивания водных масс в поверхностных водных объектах;

- о резком, «взрывообразном» увеличении интенсивности выноса загрязняющих веществ из донных отложений.

Ключевые слова: крупные водные объекты, перемешивание водных масс, загрязнения, динамика донных отложений, турбулентная диффузия, натурные измерения, трехмерное численное моделирование.

\section{Введение}

Поверхностные водные объекты, как естественные (реки, озера), так и искусственные (пруды, водохранилища), являются не только одними из основных объектов рекреации и рыбного хозяйства, но и, как правило, основным источником питьевого водоснабжения. В связи с этим особое внимание должно уделяться вопросам их загрязнения, в первую очередь экстремального, создающего непосредственную угрозу их потребительским свойствам. Базовые положения, лежащие в основе анализа этих вопросов, используемые в различных действующих нормативно-методических документах, были сформулированы более шестидесяти лет назад и не отвечают современным требованиям.

Традиционно считается, что основным механизмом переноса поллютантов в поверхностных водных объектах является фиковская диффузия, при этом концентрация и характер поллютантов не влияют на механизмы переноса. Однако выполненные в последние годы исследования показали, что эти традиционные представления дале-

\footnotetext{
* Работа выполнена при поддержке Российского фонда фундаментальных исследований, грантов № 16-41-590005 «Построение гидродинамических моделей формирования аномальных зон загрязнения в поверхностных водных объектах»; № 19-41-590013 «Исследование структуры плотностных течений и механизмов формирования слоя скачка плотности при слиянии рек с различающимися гидрохимическими характеристиками вод, находящихся в гидравлическом подпоре».
} 
ко не всегда приемлемы. В ряде случаев даже сравнительно невысокие концентрации поллютантов через изменение плотности могут принципиально изменить гидродинамику потока. Играющие в этих случаях важную роль плотностные эффекты могут иметь очень большое значение при решении прикладных водохозяйственных задач. Использование современных мощных вычислительных кластеров открывает принципиально новые возможности построения гидродинамических моделей формирования качества вод поверхностных водных объектов. Одними из самых актуальных вопросов являются следующие:

- формирование в реках (водохранилищах) не смешивающихся на значительном протяжении потоков с существенно различающимися по ряду физических и химических свойств водами $[1,7,6]$;

- механизмы формирования «залповых» выбросов загрязняющих веществ, накапливаемых в донных отложениях $[2,5]$.

Рассматривая турбулентную диффузию в реке, следует иметь в виду, что ее приповерхностное поведение (а при слабой прозрачности воды особенно важен приповерхностный транспорт массы, поскольку наблюдатель видит окрас верхних слоев воды) описывается теорией развитой турбулентности для пограничного слоя, а не в объеме. Важно, что такая теория построена для случая течения около твердой стенки (а не свободной границы) и при постоянном в объеме сдвиговом напряжении (см., например, главы IV и V в [3]; глава V посвящена задаче о теплопереносе, что в случае турбулентного пограничного слоя идентично диффузии пассивной примеси). Для описания эффективной турбулентной диффузии в реках требуется корректировка классической теории турбулентного пограничного слоя на случай течения около поверхности, на которой допустимы сдвиговые течения (отсутствие условия непроскальзывания) и, что более важно, сдвиговое напряжение не постоянно в объеме, а является линейной функцией расстояния от поверхности, обращаясь на поверхности в нуль.
Указанные явления имеют особую актуальность для территории Урала. В частности, рр. Вишера и Кама, как свидетельствуют многочисленные космо- и аэроснимки от створа слияния до территории Соликамско-Березниковского промузла, практически не перемешиваются, что имеет принципиальное значение при решении задачи регламентации техногенных воздействий этого крупнейшего в бассейне $p$. Камы источника техногенного загрязнения.

В результате длительной эксплуатации Кизеловского угольного бассейна, вследствие очень низкой эффективности проведения водоохранных мероприятий, в их водотоках-приемниках, даже в таких достаточно крупных реках, как Вильва, Яйва, Косьва, сформировались достаточно мощные техногенные донные отложения, оказывающие очень существенное влияние на гидрохимический режим данных водотоков.

Исследования, связанные с анализом материалов регулярных гидрохимических наблюдений на данных водных объектах, показали, что очень резкое «залповое», на один-два порядка, повышение содержания железа и марганца в воде этих водотоков, наблюдаемое, как правило, в феврале, конце апреля - начале мая, может объясняться только их выносом из донных отложений. В то же время традиционные оценки этих процессов, в которых в качестве основного определяющего параметра принимается коэффициент диффузии рассматриваемых поллютантов в донных отложениях, не могут дать резкий «залповый» вынос загрязняющих веществ из донных отложений в водные массы.

Натурные наблюдения в р. Каме в районе Соликамско-Березниковского промузла показали наличие в придонной области «линз» воды, характеризующихся высокой минерализацией и, соответственно, высокой плотностью. При изменении гидрологических режимов водных объектов, расположенных в зоне выклинивания Камского водохранилища, происходит их промывка. Эти явления существенно влияют на распределение полей загрязнений в данных 
наиболее техногенно-напряженных участках р. Камы. В связи с активным расширением разработки Верхнекамского месторождения калийных и магниевых руд техногенные нагрузки на р. Каму (Камское водохранилище) в виде поступления в нее избыточных рассолов будут только возрастать и, соответственно, будет увеличиваться количество загрязняющих «линз».

В то же время эти весьма актуальные вопросы остаются, как правило, за рамками традиционных исследований источников загрязнений водных объектов или являются объектами различных псевдонаучных спекуляций. Исследование указанных явлений позволит не только более объективно подойти к вопросам регламентации влияния техногенных воздействий на водные объекты, обеспечить методическую основу разработки эффективного комплекса мероприятий по их снижению, но и изучить новые гидродинамические механизмы поведения поллютантов в водных объектах. Так, группой заявителей проекта, при решении прикладной задачи улучшения качества забираемой воды на питьевом водозаборе г. Перми, удалось выявить принципиально новый тип течений. В прикладном аспекте полученные результаты могут с успехом использоваться для анализа последствий техногенных нагрузок на водные объекты РФ.

\section{1. Исследование существенного ослабления поперечного перемешивания водных масс в поверхностных водных объектах}

При слиянии рек с заметными различиями цвета воды часто можно визуаль-

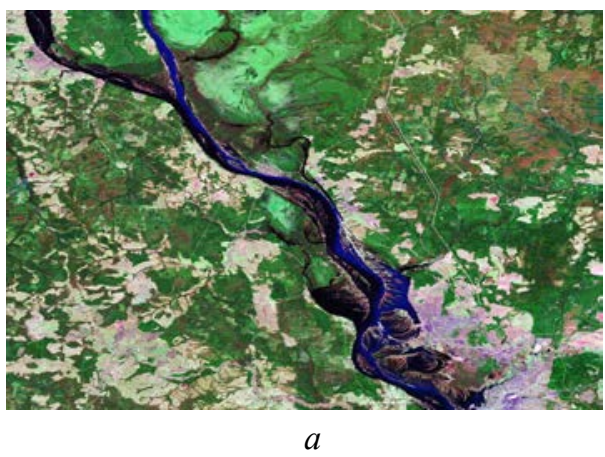

но наблюдать сравнительно низкую эффективность смешения вод вниз по течению. Важно, что различия в составе воды, определяющие цвет, достаточно малы, (рис. 1) чтобы заметно сказываться на механических свойствах вод. В типичных ситуациях можно уверенно говорить о переносе пассивного скаляра при практически однородных механических параметрах системы.

В рамках простейшей К-модели диффузии практически невозможно объяснить причины наблюдаемого различия размеров зон смешения при достаточно близких морфометрических показателях сливающихся водотоков. Проблема значительно глубже: она состоит в некорректности использования К-модели для описания рассматриваемых процессов. В связи с этим весьма актуальным становится построение альтернативных моделей взаимодействия водотоков. В рамках работы на основе грубого оценочного подхода построена перенормированная классическая теория турбулентного пограничного слоя для характерных сдвиговых напряжений.

На основе анализа масштабной инвариантности системы развито теоретическое описание пограничного слоя для линейного профиля сдвигового напряжения. Согласно этому описанию, эффективные диффузия и вязкость пропорциональны расстоянию до поверхности в степени 3/2. Такая же зависимость получается и при грубых оценках, основанных на теории турбулентного пограничного слоя около твердой стенки при однородном сдвиговом напряжении.

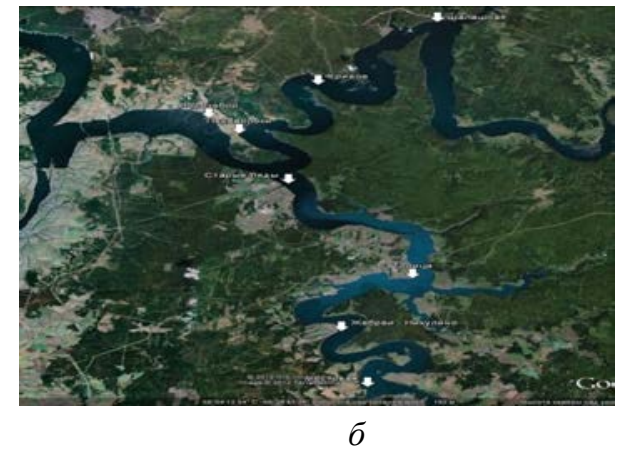

Рис. 1. Космоснимки. Слияние рек Камы, Вишеры (а) и Чусовой,Сылвы (б) 
При использовании таких оценок неизвестные эмпирические коэффициенты могут быть вычислены из известных для случая течения около твердой стенки при однородном сдвиговом напряжении. Оснований полагать, что точные значения эмпирических коэффициентов не будут отличаться от оценочных, нет, то можно предположить, что они близки к последним.

При согласованном описании турбулентной вязкости и диффузии на основе теории турбулентного пограничного слоя поле среднего течения воды и эффективной диффузии оказываются связаны. Как следствие, установившееся распределение концентрации пассивной примеси (вдали от дна и берегов) определяется безразмерным уравнением

$$
\partial_{z} \omega=y^{3 / 2} \partial_{x}^{2} \omega+\partial_{y}\left(y^{3 / 2} \partial_{y} \omega\right)
$$

где $x$ - координата поперек течения, $y$ - глубина ниже поверхности воды, Z - координата вниз по течению реки, $[x]=[y]=H \quad(H \quad-\quad$ глубина реки $), \quad$ а $[z]=\left(\beta_{3 / 2} H / \kappa_{1} \kappa_{3 / 2}\right) \ln \left[H^{3 / 2}(g \alpha)^{1 / 2} / 0,51 v\right]$. При угле уклона реки $\alpha=10^{-4}$ и $H=5$ мм, $[z] /[y] \approx 76$, то есть процесс выравнивания неоднородностей распределения концентрации поперек реки оказывается протекающим на очень большом пространственном масштабе вдоль течения реки. Расчеты на основе построенной математической модели дают характерные поля воспринимае-

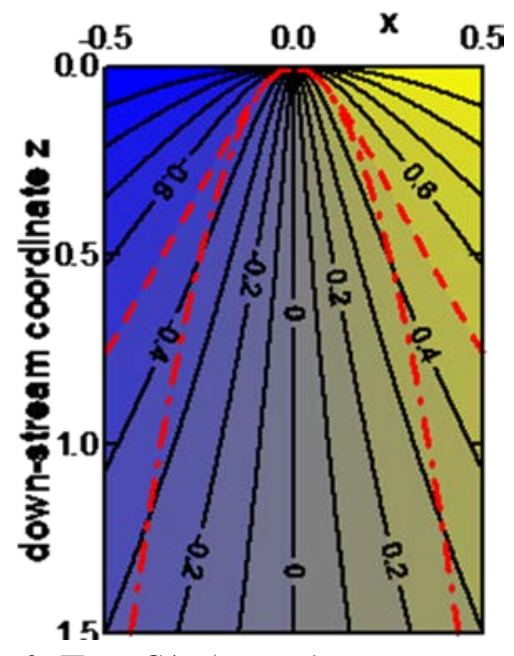

Рис. 2. Поле $C(x, z)$, определяющее цุвет воды при виде сверху, для сравнительно высокой и низкой прозрачности вод. Штриховая красная кривая: визуальная граница зоны смешения, $C= \pm 1 / 2$. Штрих-пунктирная красная кривая: визуальная граница зоны смешения для асимптотического распределения, вычисленного аналитически мого цвета вод, представленные на рис. 2.

Результаты теоретического описания сопоставлены с характерным расходом рек для заданных глубины и уклона и удовлетворительно согласуются. При типичных уклонах и глубинах рек теория, игнорирующая особенности рельефа дна, дает скорости среднего течения 1-3 м/с. Это следует рассматривать как оценку сверху для скорости течения реальных рек, в которых особенности дна могут замедлять течение до разной степени и, действительно, наблюдаются скорости 0,2-1,5 м/с (Сен-Венан первый, еще до работ Рейнольдса, указал, что для объяснения наблюдаемых в реках скоростей течений необходимо допустить наличие вихревых структур). С наблюдениями согласуются также качественные особенности профиля рек, соответствующего предлагаемому описанию.

Осуществлен групповой анализ уравнений турбулентной диффузии в турбулентном пограничном слое при линейном профиле сдвиговых напряжений. Анализ выявил единственный возможный вариант самоподобных решений. Примечательно, что все возможные самоподобные решения, допускаемые уравнениями, не могут быть локализованы по вертикальной координате: для таких решений требуется ненулевой поток примеси на бесконечности. Данная особенность решений не лишает их физического смысла; более того, толь-

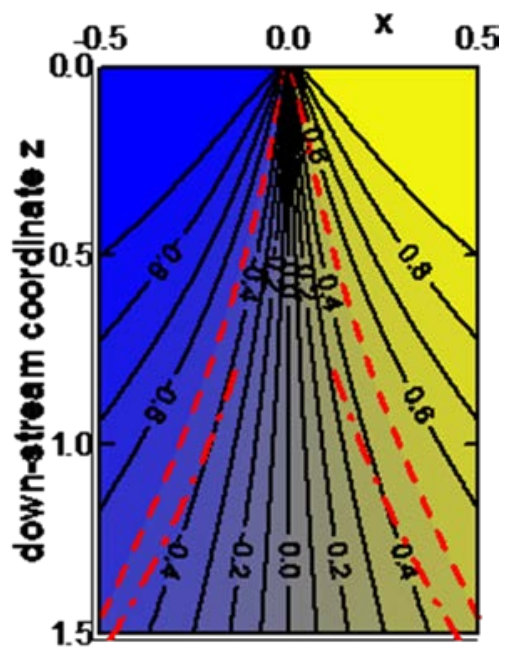


ко решения с такими свойствами и могут соответствовать физической задаче о слиянии двух рек, поскольку для такой задачи по разные стороны от зоны смешения находятся воды разных рек.

Проведены исследования уравнений для самоподобных решений без учета близости дна и берегов; найдены аналитические асимптотические самоподобные решения. Получены уравнения для самоподобных решений. Точное исследование этих уравнений оказалось возможным провести только численно, методом релаксации. Найденное численно решение сопоставлено с аналитическим асимптотическим решением; для обоих установлена ширина зоны смешивания, растущая с глубиной. На основании полученного численного решения установлена зависимость ширины зоны смешения от глубины и координаты вниз по течению реки.

Исследован вопрос о воспринимаемом цвете воды для самоподобных режимов диффузии. В связи с тем, что воспринимаемый цвет вод определяется некоторой эффективной проекцией трехмерного распределения поля пассивного скаляра на поверхность реки, вопрос о количественной характеристике этой проекции и воспринимаемой ширине зоны смешения требует отдельного рассмотрения. Установлена связь между распределением пассивной примеси и воспринимаемым цветом вод. Исследовано поведение этой зависимости для случаев очень мутных и сравнительно прозрачных вод. Найдено распределение цвета для случая асимптотического решения для распределения примеси. Установлена форма воспринимаемой зоны смеше-

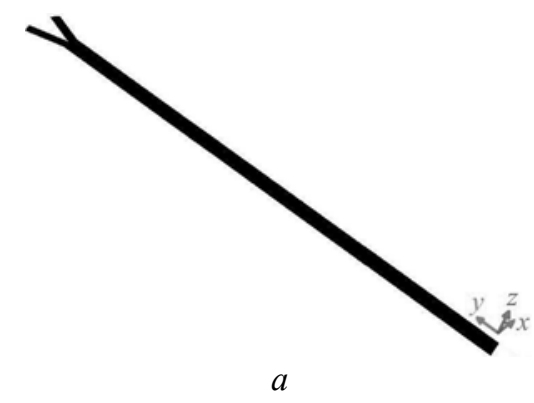

ния вод и зависимость ее ширины от координаты вниз по течению реки. Ключевые соотношения проанализированы в размерном виде, что позволяет судить о зависимости эффективности смешения от уклона реки и скорости ее течения.

Исследована задача о турбулентной диффузии с учетом близости дна и берегов: численно получены решения уравнений диффузии. Проведены численные расчеты процесса турбулентной диффузии пассивного скаляра при согласованном учете турбулентной вязкости и диффузии. Найдены поля концентрации; проанализирована зависимость процесса смешения от ширины реки: установлено, что поздние стадии смешения в узких реках протекают существенно быстрее, чем в широких.

Исследованы визуальные структуры на поверхности реки. Для найденных полей концентрации вычислены поля воспринимаемого цвета при малой и высокой прозрачности вод. Проанализированы закономерности расширения видимой зоны смешения.

\section{2. Трехмерное численное моделирование влияния гидродинамических режимов на смешение вод сливающихся рек \\ Для изучения течений в зонах слияния рек Камы и Вишеры (Пермский край, Россия), характеризующихся близкими плотностями и расходами воды, проведе- ны расчеты для модельной конфигурации в случае двух рек, характеризующихся та- кими же пространственными размерами, что и реки Кама и Вишера, но с прямоли- нейными участками русла [1] (рис. 3).}

Рис.3. Расчетная область (а) и фрагмент расчетной сетки (б); для лучшей визуализации вертикальный размер увеличен в 100 раз 
Вычисления проводились для участка протяженностью 13 км. Глубина рек принималась постоянной на протяжении всей вычислительной области и равной 17 метрам. В рамках работы исследован механизм ослабления поперечного смешения, основанный на вторичных течениях второго рода по Прандтлю. При этом в поперечном сечении потока формируются вихри противоположного направления, а пространство между этими вихрями играет роль своеобразной жидкой стенки, препятствующей смешению сливающихся потоков. Наличие таких структур было зафиксировано в натурных исследованиях на р. Каме ниже ее слияния с р. Вишерой. Трехмерное численное моделирова- ние подтвердило, что в зоне слияния двух рек с близкими плотностями и химическими составами вод могут формироваться устойчивые поперечные вторичные вихревые структуры (рис. 4).

Интенсивность этого вторичного течения гораздо ниже, чем основного продольного течения, однако, оно может приводить к существенному ослаблению поперечного смешения. Если вторичные структуры не образуются, то смешение вод сливающихся потоков происходит значительно интенсивней. Основными факторами, влияющими на формирование вторичных структур, являются особенности морфометрии рассматриваемого участка и его гидрологического режима (рис. 5, 6).
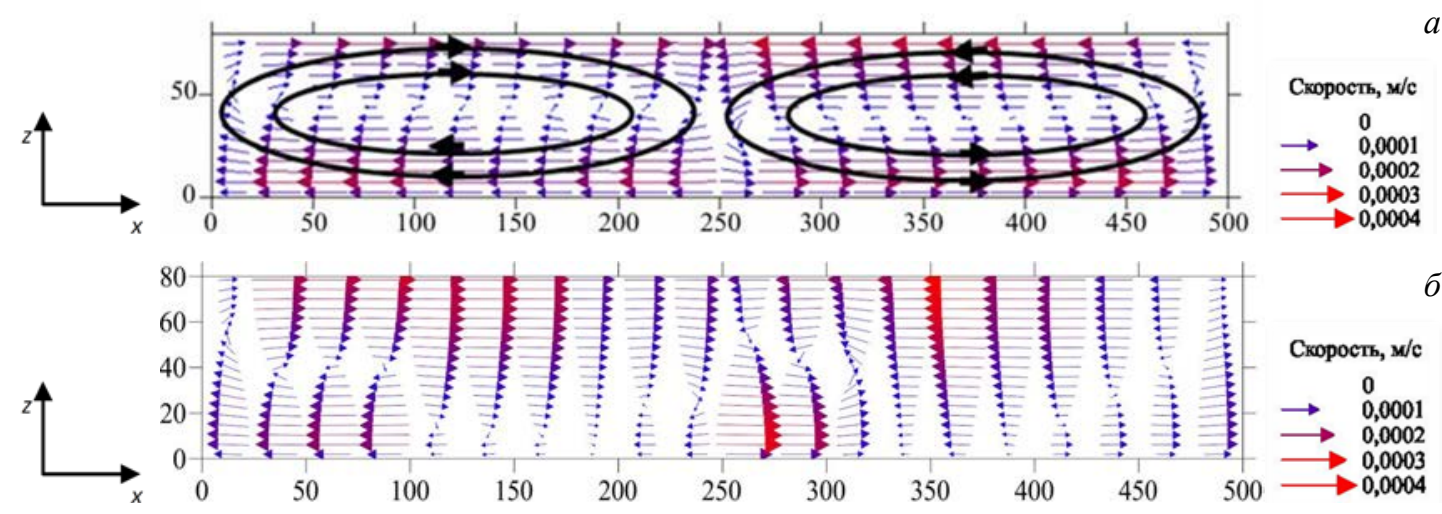

Рис.4. Структура вторичного течения в поперечном сечении для скорости течения вод сливающихся рек 0,2 м/с на различных расстояниях от места слияния, м: 700 (а), 10000 (б); для лучшей визуализации вертикальный размер сетки увеличен в 10 раз
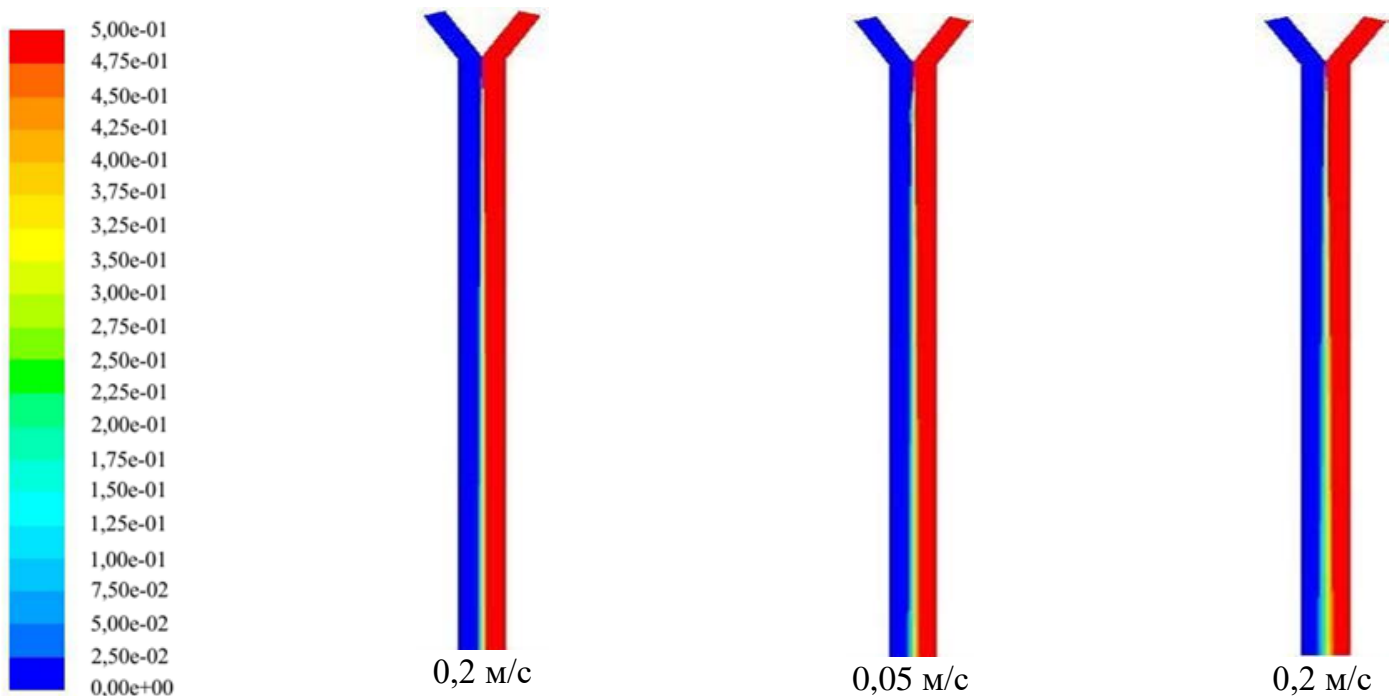

Рис.5. Поля концентрации примеси на нижней границе расчетной области при различных скоростях сливаюшихся рек; протяженность русла после слияния 10 км; пространственный масштаб вдоль русла рек уменьшен в два раза 

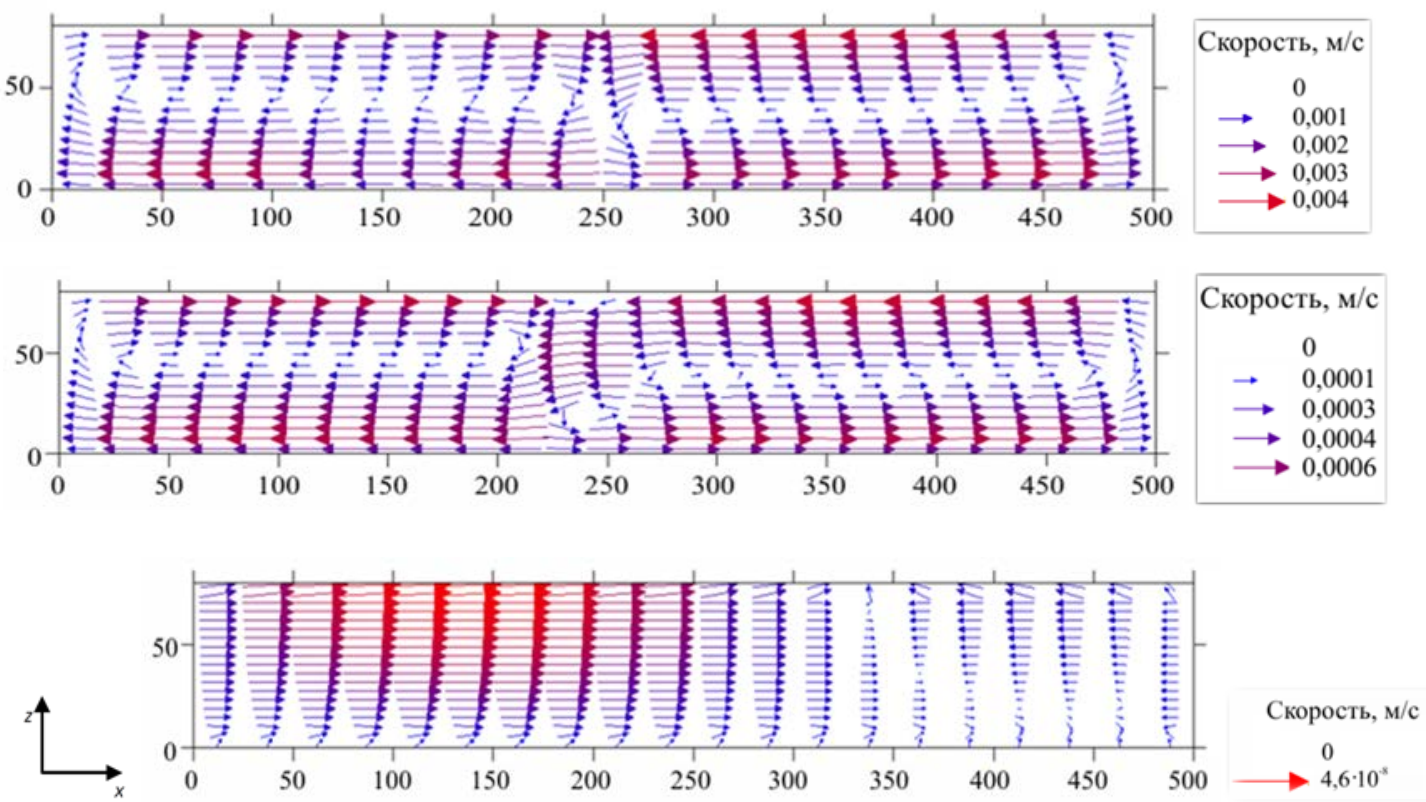

Рис.6. Векторные поля скорости в вертикальном сечении вод сливающихся рек на расстоянии 700 м от места слияния при различных скоростях, м/с: 0,2 (a); 0,05 (б); 0,000005 (в); для лучшей визуализачии вертикальный размер сетки увеличен в 10 раз

В рамках выполнения работ по трехмерному численному моделированию поперечного перемешивания при слиянии рек с учетом плотностных эффектов и реальной геометрии русел изучены течения в зонах слияния рек Камы и Вишеры (Пермский край, Россия), характеризующихся близкими плотностями и расходами воды, и рек Чусовой и Сылвы (Пермский край, Россия), характеризующихся сильно различающимися гидрохимическими режимами. Для рек Камы и Вишеры имеются данные космоснимков, на которых четко прослеживается динамика смешения рек в районе слияния, поскольку воды рек различаются по оптической плотности.

В рамках работы исследован механизм ослабления поперечного смешения, основанный на вторичных течениях второго рода по Прандтлю. При этом в поперечном сечении потока формируются вихри противоположного направления, a пространство между этими вихрями играет роль своеобразной жидкой стенки, препятствующей смешению сливающихся потоков. Наличие таких структур было зафиксировано в натурных исследованиях на p. Каме ниже ее слияния с р. Вишерой.
Трехмерное численное моделирование подтвердило, что в зоне слияния двух рек с близкими плотностями и химическими составами вод могут формироваться устойчивые поперечные вторичные вихревые структуры. Интенсивность этого вторичного течения гораздо ниже, чем интенсивность основного продольного течения, однако оно может приводить к существенному ослаблению поперечного смешения. Если вторичные структуры не образуются, то смешение вод сливающихся потоков происходит значительно интенсивней. Основными факторами, влияющими на формирование вторичных структур, являются особенности морфометрии рассматриваемого участка и его гидрологического режима.

Для рек Чусовой и Сылвы, с сильно различающимися гидрохимическими режимами, расчеты показали, что при больших скоростях течения (в период паводка), ниже места слияния воды рек текут вниз по течению, практически не перемешиваясь на всем исследованном участке (13 км). При малых и умеренных расходах более тяжелые воды реки Сылвы, характеризующиеся большей минерализацией, распространяются вблизи дна, причем, такое течение наблюдается не только 
вниз по течению от места слияния, но и вверх по течению реки Чусовой. Менее плотные воды реки Чусовой, характеризующиеся меньшей минерализацией, движутся в приповерхностном слое как вниз по течению от места слияния, так и вверх по течению реки Сылвы.

\section{3. Динамика донных отложений и ее роль в формировании залповых выбросов загрязняющих веществ в водотоках}

Интенсивность поступления загрязняющих поллютантов в водную массу при размыве донных отложений описывается следующим соотношением:

$$
\mathrm{qC}_{i}=-\varepsilon \cdot \frac{\partial Z}{\partial t} \cdot \mathrm{C}_{i}\left[\frac{\mathrm{M} \Gamma}{\mathrm{M}^{2} \cdot \mathrm{c}}\right],
$$

где поток $i$-поллютанта при размыве донных отложений;

$\varepsilon-$ пористость донных отложений;

$\mathrm{Ci}$ - концентрация $i$-поллютанта в поровом растворе;

$Z$ - мощность донных отложений.

Таким образом, основные компоненты при расчете потока загрязняющих веществ, образуемых при размыве донных отложений, определяются интенсивностью их размыва. Поэтому основное внимание должно быть уделено описанию динамики донных отложений в реках с подвижным аллювием.

В качестве объекта, на котором проводилась отладка моделей, была выбрана река Чепца в районе пос. Балезино, характеризующаяся высокой подвижностью дна и достаточной однородностью донных отложений, что существенно упрощает выполнение расчетов.

\section{4. Общая характеристика используемой гидродинамической модели для описания динамики донных отложений}

В настоящее время одним из наиболее эффективных инструментов расчета динамики донных отложений является применение гидродинамических моделей в приближении «мелкой воды».
В связи с этим двумерная (в горизонтальной плоскости) модель участка p. Чепца в районе пос. Балезино построена на основе лицензированного, специализированого, гидрологического программного пакета SMS v.11.1 (Surfacewater Modeling System) американской компании AQUAVEO LLC, предназначенного для моделирования распространения загрязнения и транспорта взвешенных и влекомых наносов в водном объекте в двухмерном приближении. В ее основе лежат несколько модулей (ADH, RMA2, RMA4, FESWMS, TUFLOW (ра3работка BMT WBM), RiverFlow2D (разработка Hydronia LLC), и другие), которые позволяют решать различные задачи.

Задание исходных данных. Для корректного задания морфометрии рассматриваемого водного объекта были использованы материалы детальной эхолотной съемки. Обработка первичных материалов осуществлялась в программном комплексе ArcGIS v.10.1. Производилась доработка полученных векторных данных (берегов, изолиний, точек глубин водного объекта) в виде шейп файлов.

В программном комплексе SMS v.11.1 в специальном модуле «Мар» произведена конвертация полученных ранее шейп-файлов во внутренний формат программы для дальнейшего использования при создании модели.

Далее для наиболее полного и эффективного задания особенностей морфометрии участка р. Чепца в районе пос. Балезино на расчетной области построена треугольная сетка со средней длиной ребра элемента 4 метра, состоящая из 79839 элементов. Расчет основных гидродинамических характеристик и распространения транспорта наносов проводится при среднемноголетних характеристиках разной обеспеченности.

Исходные данные при моделировании. Гидродинамическая модель построена для участка р. Чепца, в районе пос. Балезино (рис. 8,9). Его характерные размеры: общая длина 2350 м, ширина варьируется от 140 до 320 м. 
Для моделирования транспорта наносов использован гранулометрический состав двух проб грунта взятых на участке моделирования, (таблица).

В расчете используются следующие методы осаждения наносов, переноса несвязанных донных наносов методом Маер-Питера и Мюлера.
В работе 2017 года была выбрана для отработки технологии моделирования русловых процессов р. Чепца в районе пос. Балезино, где лимитирующим фактором является заиление русла, создающее угрозу устойчивой работе основного водозабора данного населенного пункта.

Река Чепца в районе пос. Балезино

Таблицุа

Физико-механические свойства грунтов

\begin{tabular}{|c|c|c|c|c|c|c|c|c|c|c|c|}
\hline \multirow{3}{*}{$\begin{array}{l}\text { Наименование и } \\
\text { номер выработки }\end{array}$} & \multicolumn{11}{|c|}{ Гранулометрический состав } \\
\hline & \multirow{2}{*}{$\begin{array}{c}\text { Галька } \\
60-10\end{array}$} & \multicolumn{2}{|c|}{ Гравий } & \multicolumn{5}{|c|}{ Песок } & \multicolumn{2}{|c|}{ Пыль } & \multirow{2}{*}{$\begin{array}{l}\text { Глина } \\
<0,002\end{array}$} \\
\hline & & $\begin{array}{c}10- \\
5\end{array}$ & $\begin{array}{l}5- \\
2\end{array}$ & $2-1$ & $\begin{array}{c}1,0- \\
0,5\end{array}$ & $\begin{array}{l}0,5- \\
0,25\end{array}$ & $\begin{array}{c}0,25- \\
0,1\end{array}$ & $\begin{array}{l}0,1- \\
0,05\end{array}$ & $\begin{array}{l}0,05- \\
0,01\end{array}$ & $\begin{array}{l}0,01- \\
0,002\end{array}$ & \\
\hline $\begin{array}{c}\text { Проба №1 } \\
\text { р. Чепца в р-не } \\
\text { водозаборных } \\
\text { сооружений }\end{array}$ & - & - & - & 9,80 & 3,97 & 48,08 & 25,80 & 5,20 & 4,30 & 1,43 & 1,43 \\
\hline $\begin{array}{c}\text { Проба №2 } \\
\text { р. Чепца в 1,2 км } \\
\text { выше водозаборных } \\
\text { сооружений }\end{array}$ & - & - & - & 0,00 & 0,60 & 2,95 & 5,15 & 41,28 & 27,00 & 15,88 & 7,15 \\
\hline
\end{tabular}

Гидродинамическая модель участка p. Чепца в районе пос. Балезино (2018).

Динамика аллювиальных речных русел определяется в конечном итоге соотношением динамических и удерживаемых сил, действующих на каждую твердую частицу в потоке.

Применение современных вычислительных технологий решения задач гидродинамики в 2D-приближении с подвижными границами позволило подойти к практическому решению задач динамики русел с учетом активного взаимодействия потока и аллювиального русла.

Большинство рек, в том числе и средней полосы России, характеризуются значительной внутригодовой неравномерностью стока. За достаточно короткий период прохождения весеннего половодья проходит более половины годового стока, поэтому модели русловых процессов должны учитывать эту внутригодовую неравномерность распределения расходов воды. Принципиальная перестройка русла происходит при максимальных расходах воды, характеризующихся, как правило, незначительной временной продолжительностью. Данное положение обусловило появление понятия «руслоформирующие расходы воды». имеет аллювиальное русло, в основе которого преобладает песок (в основном средний песок $\mathrm{D} \sim 0,5 \mathrm{MM})$, в то же время питьевое водоснабжение пос. Балезино осуществляется из р. Чепца, водозабор располагается в 700 м ниже автодорожного моста через нее. Практически каждый год после прохождения весеннего половодья русло в районе водозаборных сооружений заносится и мелеет, что сказывается на работе водозабора. Поэтому перед нами встала задача оценить с помощью современных вычислительных методов характерные размеры переформирования русла из-за весенних паводков.

В 2018 году гидродинамическая модель транспорта наносов для участка p. Чепца в районе водозаборных сооружений пос. Балезино калибровалась с использованием данных гидродинамических характеристик прошедшего весеннего половодья 2018 года и новой батиметрической съемки, сделанной летом 2018 года.

Основные допущения, связанные с данной версией модели RiverFlow2D:

- При использовании опции влекомых наносов скорость переноса притока осадка равна транспортирующей емкости в условиях равновесия. 
- Размер каждой частицы осадка рассматривается с использованием как одного характеристического диаметра $\left(D_{50}\right)$, так и трех характерных размеров $\left(D_{30}, D_{50}, D_{90}\right)$.

Поскольку формулировки для потока транспорта влекомых наносов, потока взвешенных наносов и скорость осаждения основаны на детерминированных законах, поддерживаемых экспериментами, для каждой из них были учтены факторы параметров настройки. Следовательно, модель позволяет откалибровать расчетный транспорт наносов для каждой конкретной ситуации.

Для калибровки модели взята построенная в 2017 году гидродинамическая модель для участка р. Чепца, в районе пос. Балезино, с его характерными размерами: общая длина 2350 м, ширина варьируется от 140 до 320 м, а для описания наиболее важных участков проводилось сгущение сетки до средней длины ребра элемента 3 метра. Для задания морфометрий модели использовалась цифровая модель рельефа 2017 года, сделанная в ходе топогеодезических и гидрологических работ в июле 2017 года (рис. 7).

Для решения поставленной задачи необходимы следующие данные:

- физико-механические свойства грунта;

- гидродинамические характеристики р. Чепца в районе пос. Балезино.

Для моделирования транспорта наносов использован гранулометрический со- став двух проб грунта, взятых на участке моделирования в ходе проведенных топогеодезических и гидрологических работ в июле 2017 года (см. табл.).

Расчет производился по гидродинамическим характеристикам p. Чепца в районе пос. Балезино, весеннее половодье 2018 года, представленным на рис. 8, 9 Расчетное время - 50 суток.

Калибровка морфодинамической модели заключается в подборе поправочного коэффициента таким образом, чтобы расчетная модель наиболее близко моделировала реальные изменения русла. Для этого приходится проводить множество расчетов с разным значением поправочного коэффициента с целью добиться сходства по пикам изменения дна и зонам их расположения в сравнении с реальными изменениями.

В общей сложности было проведено 7 калибровочных расчетов. Каждый занимал примерно около 5 суток, потом строилась картосхема изменения дна, и далее происходило сравнение картосхемы расчетных данных с картосхемой реального изменения дна, полученной в ходе сравнения выполненной батиметрической съемки в августе 2018 года с батиметрической съемкой июля 2017 года. Если получались сильные расхождения, то поправочный коэффициент менялся и происходил повторный перерасчет.

Для того чтобы показать, как неравномерно происходит переформирование рус-

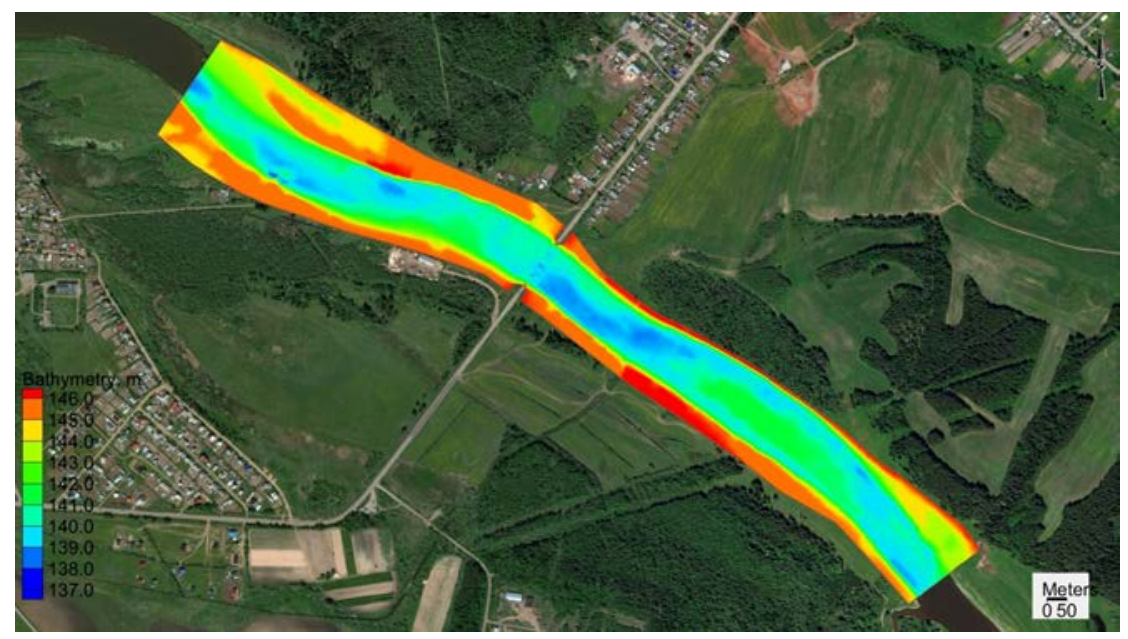

Рис.7. Морфометрия моделируемого участка р. Чепца, в районе пос. Балезино 
ла реки по ширине и длине, на рис. 10 представлена картосхема неравномерности распределения изменения дна (размыв русла и аккумуляция наносов), полученная в ходе сравнения двух батиметрических съемок июля 2017 года и августа 2018 года.

Картосхемы изменения дна (размыв русла и аккумуляция наносов) в русле p. Чепца в районе пос. Балезино в начальный момент времени и другие расчетные моменты времени 25 и 50 суток представлены на рис. 10-12.

Из расчетных данных, на рис. 10, 11 следует, что наибольшая интенсивность изменения морфометрии русла наблюдается во время прохождения пика половодья, а в фазе спада половодья интенсивность русловых процессов падает.

В целом, проведенные модельные расчеты достаточно хорошо воспроизводят процессы изменения дна в районе водоза- бора. Так, для принятых условий на p. Чепца в районе водозаборных сооружений за период паводка аккумуляция наносов может достигать порядка $\sim 0,1 \mathrm{м}$.

Проведенные расчеты показали, что вследствие специфических особенностей гранулометрического состава донных отложений русло р. Чепца в районе пос. Балезино характеризуется высокой подвижностью.

Для принятых условий на р. Чепца в районе водозаборных сооружений за период весеннего половодья 2018 года разница в расхождении величин размыва русла и аккумуляции наносов составляет порядка $10 \%$, при сравнении разницы между батиметрическими съемками 2017, 2018 годов и разницы между калибровочным модельным расчетом с батиметрической съемкой 2017 года.

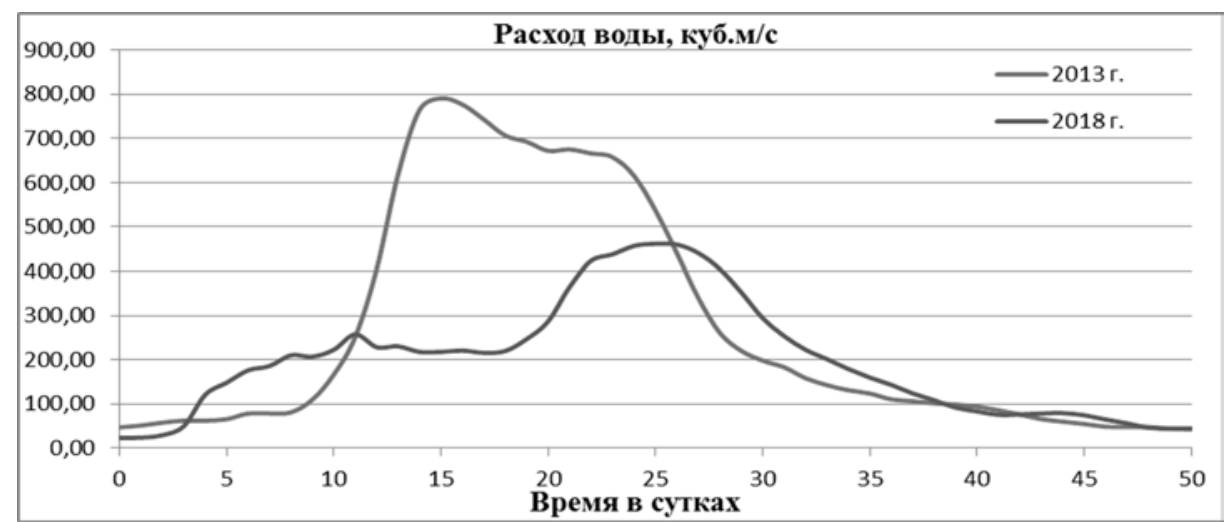

Рис. 8. Расход воды р. Чепия в районе пос. Балезино, весеннее половодье 2013 года и 2018 года для сравнения

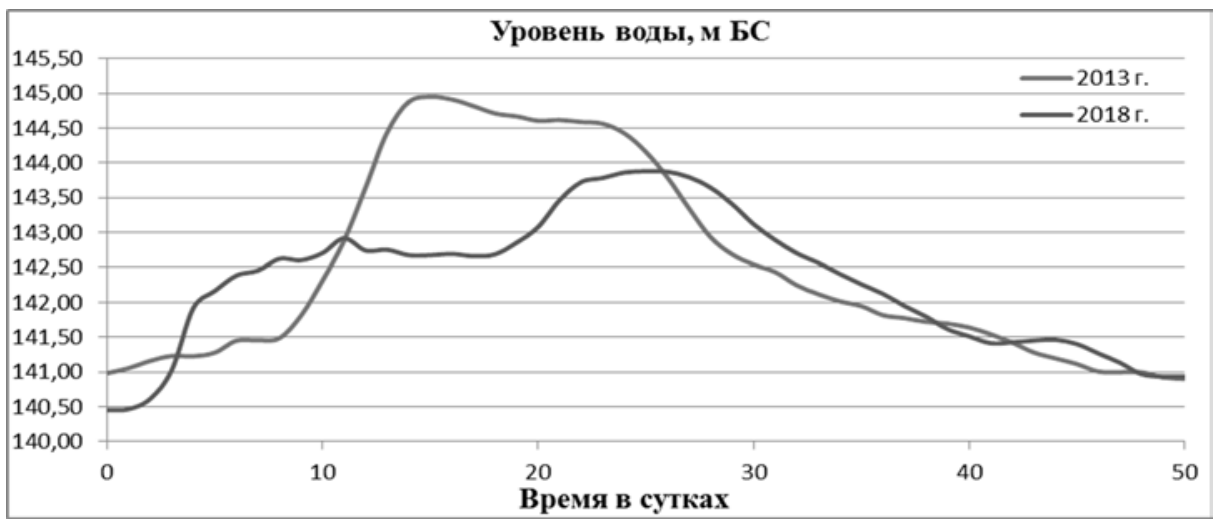

Рис.9. Уровень воды р. Чепияа в районе пос. Балезино, весеннее половодье 2013 года и 2018 года (для сравнения) 




Рис. 10. Картосхема неравномерности распределения изменения дна (размыв русла и аккумуляция наносов), полученная в ходе сравнения двух батиметрических съемок июля 2017 г. и августа 2018 г.

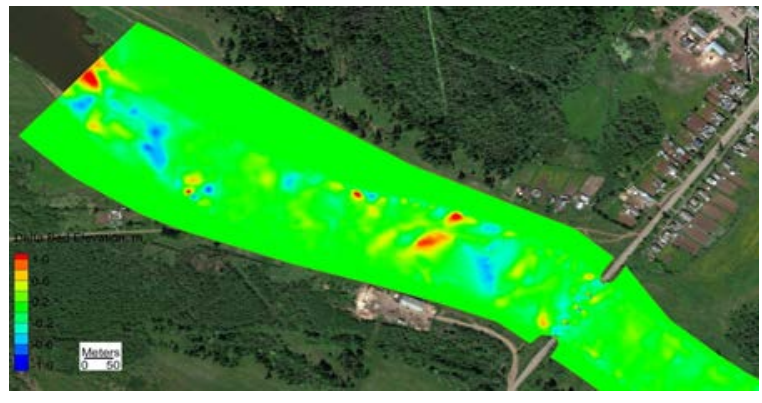

Рис.11. Картосхема изменения дна (размыв русла и аккумуляция наносов) в расчетный момент времени 25 суток

Следует отметить, что моделирование динамики морфометрии водотоков предполагает сглаживание и нивелирование пиков, которые могут быть в реальных условиях. В целом, данная откалиброванная модель р. Чепца в районе пос. Балезино может использоваться для проведения различных модельных расчетов.

\section{5. Трехмерное численное моделирование залпового выноса поллютантов из донных отложений}

В рамках трехмерного подхода проводилось также численное моделирование залпового выноса поллютантов из донных отложений вследствие наступления неустойчивости потока воды над слоем загрязненных донных отложений, моделируе-

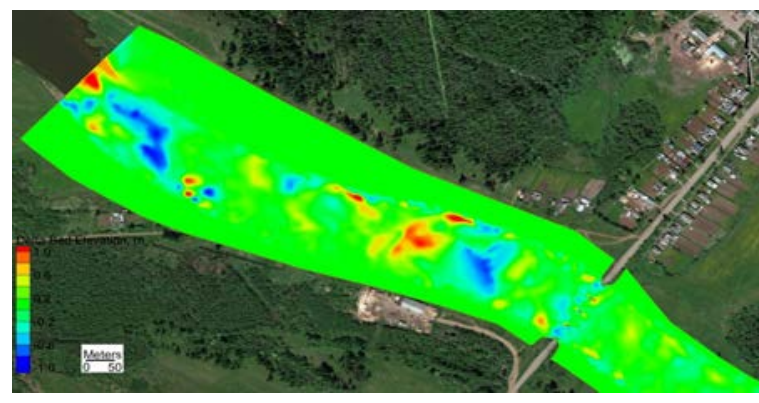

Рис. 12. Картосхема изменения дна (размыв русла и аккумуляция наносов)

в расчетный момент времени 50 суток

мом как слой пористой среды, насыщенной жидкостью, содержащей примеси (загрязняющие вещества). На первом этапе проводилось моделирование выноса загрязнений из слоя придонной растительности, в этом случае расчеты проводились для достаточно больших значений проницаемости пористой среды. Рассматривался участок реки с горизонтальными размерами $100 \times 100$ м, глубина реки составляла 4 метра. Толщина слоя растительности принималась равной 2 м. Расчеты показали (рис. 13), что при достижении некоторого критического значения скорости потока наблюдается образование крупномасштабного вихря вблизи входа расчетной области. Этот вихрь охватывает как слой чистой жидкости, так и слой придонной 
$100 \mathrm{c}$

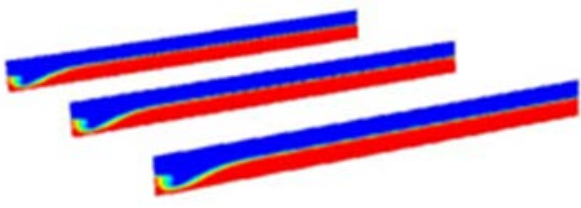

$1300 c$
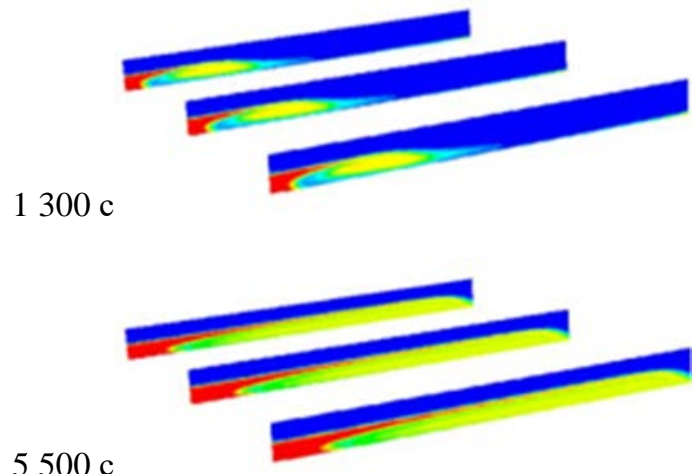

$700 \mathrm{c}$

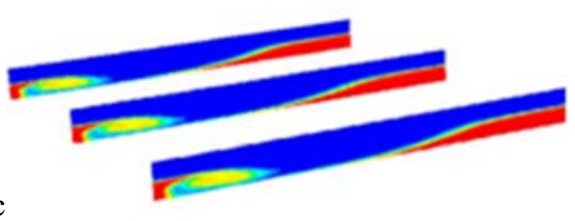

$1900 \mathrm{c}$
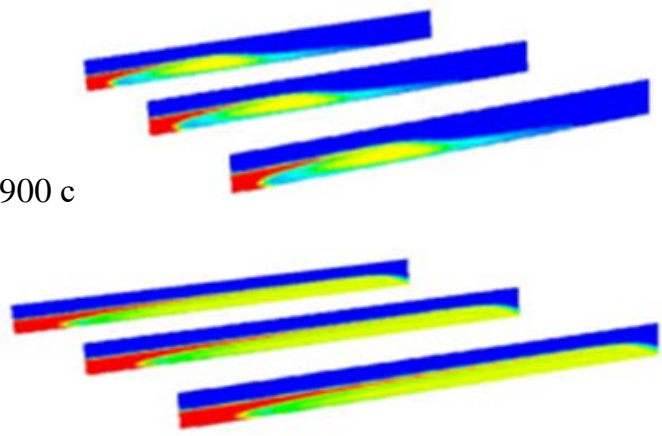

$7300 \mathrm{c}$

Рис.13. Распределение конщентрации примеси в вертикальных сечениях по краям и посередине расчетной области

растительности, приводя к залповому выносу загрязняющих примесей из слоя придонной растительности. С течением времени образовавшийся вихрь перемещается с основным потоком, вынося загрязнения из толщи растительности вниз по потоку.

На втором этапе проводилось моделирование залпового выноса загрязнений в результате неустойчивости потока воды над слоем донных отложений, представляющих собой песок. Расчеты проводились для участка реки глубиной 2 м, толщина слоя песка на дне принималась равной 1 м, горизонтальные размеры расчетной области составляли $50 \times 100$ м. Вычисления показали, что при увеличении скорости потока до $0,5 \mathrm{~m} / \mathrm{c}$ наблюдается неустойчивость, приводящая к формированию крупномасштабного вихря и залповому выносу загрязнений из слоя песка. Вынесенные из слоя песка загрязнения перемещаются с потоком вниз по течению.

\section{Заключение}

Работа посвящена разработке гидродинамических моделей возникновения аномальных зон загрязнения в поверхностных водных объектах. Для достижения указанных целей работы проводились исследования по двум направлениям: исследование механизмов ослабления поперечного перемешивания водных масс в поверхностных водных объектах; исследование формирования аномальных зон загрязнения в поверхностных водных объектах, связанного с резким, «взрывообразным» увеличением интенсивности выноса загрязняющих веществ из донных отложений.

В рамках первого направления теория турбулентного пограничного слоя модифицирована на случай течения вблизи свободной поверхности при заданном линейном профиле сдвигового напряжения (на поверхности сдвиговое напряжение обращается в нуль). На основе данной теории описаны турбулентные вязкость и диффузия в верхних слоях рек, построено математическое описание процесса диффузионного смешения вод сливающихся рек выведено уравнение эволюции поля концентрации и граничные условия для него.

Для приповерхностной области, где близость дна еще не начинает сказываться на турбулентной диффузии, смешение вод сливающихся рек имеет самоподобный характер. Численно найдено распределение концентрации для такого самоподобного режима и аналитически вычислена асимптотическая форма этого распределения.

Рассмотрен вопрос о визуально воспринимаемом цвете рек при ограниченной прозрачности. Для зависимости ширины зоны смешения от координаты вниз по течению установлен переход от корневой за- 
висимости, наблюдаемой вблизи точки слияния, к квадратичной, наблюдаемой в области, где расстояние рассеяния света в воде мало по сравнению с характерной шириной зоны смешения. Проведены сбор и анализ исходных данных по существенному ослаблению поперечного перемешивания при разных гидрологических режимах. В качестве исходных данных использовались крупномасштабные космо- и аэроснимки. Найдено, что в некоторых случаях сливающиеся потоки не перемешиваются на значительных расстояниях (от 10 до 100 километров) от места слияния.

Впервые проведено исследование полей скорости в р. Каме на участке ниже ее слияния с р. Вишерой. Выполнено трехмерное численное моделирование влияния гидродинамических режимов на процессы поперечного смешения вод при слиянии крупных рек. При этом впервые в рамках вычислительного эксперимента на модели с размерами реального крупного водного объекта удалось воспроизвести и визуализировать формирование вторичных течений второго рода, представляющих собой устойчивые поперечные вихревые структуры. Наличие таких структур позволяет объяснить значительное ослабление интенсивности поперечного перемешивания, наблюдаемое при слиянии ряда рек. Основными факторами, влияющими на формирование вторичных структур, являются особенности морфометрии рассматриваемого участка и его гидрологического режима.

В рамках второго направления проведены исследования характера формирования техногенных донных отложений, динамики в них поллютантов, в условиях изменения окислительно-восстановительного потенциала, построены гидродинамические модели сопряжения потоков поллютантов в водной массе и донных отложениях; выполнено трехмерное численное моделирование выноса поллютантов из донных отложений. Показано, что при достижении некоторого критического значения скорости основного течения в реке возникает неустойчивость, в результате которой в потоке возникают крупномасштабные вихри, приводящие к внезапному выносу загрязнений из донных отложений.

\section{Библиографический список}

1. Аполлов Б.А. Учение о реках. - М.: Изд-во МГУ, 1951. -522 с.

2. Караушев А.В., Меерович Л.Н., Серков Н.К. Моделирование зон распространения неконсервативных загрязняющих веществ в водоемах // Тр. ГГИ, 1982. - Вып. 283. - С. 116-125.

3. Ландау Л.Д., Лифиии Е.М. Теоретическая физика. - Т. 6. Гидродинамика. - М., Наука, 1986.

4. Любимова Т.П., Паршакова Я.Н., Лепихин А.П., Гуалтьери К., Лэйн С., Ру Б. Влияние гидродинамических режимов на смешение вод сливающихся рек // Вычислительная механика сплошных сред. - 2018. - Т. 11. - № 3. - С. 354-361.

5. Best J.L. Sediment transport and bed morphology at river channel confluences // Sedimentology. - 1988. Vol. 35. - № 3. P. 481-498.

6. Constantinescu G., Miyawaki Sh., Rhoads B., Sukhodolov A., Kirkil G. Structure of turbulent flow at a river confluence with momentum and velocity ratios close to 1: Insight provided by an eddy-resolving numerical simulation // Water Resour. - Res. 2011. - Vol. 47. - № 5. - W05507.

7. Leite Ribeiro M., Blanckaert K., Roy A.G., Schleiss A.J. Flow and sediment dynamics in channel confluences // J. Geophys. - Res. 2012. - Vol. 117. - № F1. F01035. 


\title{
CONSTRUCTION OF HYDRODYNAMIC MODELS FORMING ANOMALOUS CONTAMINATION ZONES IN SURFACE WATER OBJECTS
}

\author{
T.P. Lyubimova ${ }^{1}$, Ya.N. Parshakova ${ }^{1}$, D.S. Goldobin ${ }^{1}$, A.P. Lepikhin ${ }^{2,3}$ \\ ${ }^{1}$ Institute of Continuous Media Mechanics UB RAS \\ ${ }^{2}$ Mining Institute UB RAS \\ ${ }^{3}$ Perm State National Research University
}

The work is devoted to the building of hydrodynamic models for the formation of anomalous pollution zones in surface water bodies. The aim of the study is to establish the physical mechanisms and conditions under which the formation of such zones is observed. The specific tasks are as follows:

- significant weakening of the transverse mixing of water masses in surface water bodies;

- sharp «explosive» increase in the intensity of the removal of pollutants from bottom sediments.

Keywords: large water bodies, mixing of water masses, pollution, bottom sediment dynamics, turbulent diffusion, field measurements, three-dimensional numerical simulation.

\section{Сведения об авторах}

Любимова Татьяна Петровна, доктор физико-математических наук, профессор, заведующий лабораторией, Институт механики сплошных сред УрО РАН - филиал Пермского федерального исследовательского центра УрО РАН (ИМСС УрО РАН), 614013, г. Пермь, ул. Академика Королева, 1; e-mail: lyubimovat@mail.ru

Паршакова Янина Николаевна, кандидат физико-математических наук, старший научный сотрудник, ИМСС УрО РАН; e-mail: parshakova@icmm.ru

Голдобин Денис Сергеевич, кандидат физико-математических наук, старший научный сотрудник, ИМСС УрО РАН; e-mail: denis.goldobin@gmail.com

Лепихин Анатолий Павлович, доктор географических наук, профессор, заведующий лабораторией проблем гидрологии суши, Горный институт УрО РАН - филиал Пермского федерального исследовательского центра УрО РАН (ГИ УрО РАН), 614007, г. Пермь, ул. Сибирская, 78А; профессор кафедры гидрологии и охраны водных ресурсов, Пермский государственный национальный исследовательский университет (ПГНИУ), 614990, г. Пермь, ул. Букирева, 15; e-mail: lepihin49@mail.ru 